\title{
Stress, severity of illness, and outcome in ventilated preterm infants
}

Department of Neonatal Medicine and Surgery,

Nottingham City

Hospital,

Nottingham

D Barker

N Rutter

Correspondence to: Dr Barker,

Department of Child Health, E Floor, East Block, Queen's Medical Centre,

Accepted 29 August 1996

\author{
D P Barker, N Rutter
}

lated preterm infants, and to compare responses between infants with different clinical outcomes.

Methods-Physiological and hormonal stress responses were studied in 47 ventilated preterm infants who were judged clinically to require sedation. The correlation between the stress response and severity of illness was examined, and responses were compared between infants with different clinical outcomes.

Results-Stress hormone concentrations were significantly correlated with severity of illness, assessed using the arterial:alveolar oxygen partial pressure ratio. Noradrenaline showed the strongest correlation, with an exponential pattern of increased secretion. Catecholamine concentrations before sedation were significantly higher among infants who subsequently died ( $n=15$, at a median age of 6 days) than among survivors: median noradrenaline 4.31 vs $2.16 \mathrm{nmol} / 1$, median adrenaline 0.69 vs $0.31 \mathrm{nmol} / \mathrm{l}$. The observed fall in noradrenaline with sedation was lower among those who died than survivors (median fall $2 \%$ vs $40 \%$ ).

Conclusion-Preterm infants are capable of hormonal stress responses appropriate for the severity of their illness. Extreme catecholamine responses, in the sickest infants, are associated with the worst outcome.

(Arch Dis Child 1996;75:F187-F190)

Keywords: stress, pain, hormonal response.

The ability of newborn infants to mount hormonal and metabolic stress responses to surgery was demonstrated by Anand and colleagues in the $1980 \mathrm{~s}^{12}$ Responses vary in direct proportion to the degree of surgical stress. ${ }^{3}$ Responses to other types of stress have received comparatively little attention, and it is unclear whether Anand's findings can be extrapolated to preterm infants receiving intensive care. Sources of stress for these infants include respiratory disease and recurrent invasive procedures, ${ }^{4}$ yet some appear unable to produce appropriate responses. ${ }^{5}$

Whether the stress response helps or hinders preterm infants receiving intensive care is an important question, as opiate sedation and analgesia have been advocated for ventilated infants, and are effective in lowering stress hormone concentrations. ${ }^{67}$ The aim of this study was to investigate the correlation between severity of illness and stress responses in venti-

\section{Methods}

Forty seven preterm infants (26 boys) receiving mechanical ventilation on the neonatal intensive care unit of Nottingham City Hospital were studied. They were of median gestational age 28 weeks (range 24 to 35 ) and median birthweight $(1.14 \mathrm{~kg}$, range 0.52 to 3.05). Twenty three infants were delivered vaginally and 24 by caesarean section, with 36 (77\%) mothers having received dexamethasone before delivery. Respiratory distress syndrome was the predominant clinical diagnosis, with $42(89 \%)$ infants treated postnatally with surfactant.

Infants became eligible for inclusion when a decision was made by the clinical team to start sedation, based on the level of ventilatory support required and the infants' perceived distress judged by spontaneous activity and responses to handling (none was receiving muscle relaxants). An indwelling arterial line and no previous opiate treatment were additional entry criteria. The sedation regimen consisted of an intravenous bolus of diamorphine given over 30 minutes via syringe pump, followed by a continuous diamorphine infusion. Twenty five infants were included in a concurrent study comparing physiological and hormonal responses to two different loading doses (in which no significant difference in hormonal responses between dose regimens was found) ${ }^{8}$ Thus 34 infants received a bolus dose of $50 \mathrm{mcg} / \mathrm{kg}$, while 13 received a 200 $\mathrm{mcg} / \mathrm{kg}$ dose. In all cases the continuous infusion was started at $15 \mathrm{mcg} / \mathrm{kg} / \mathrm{hour}$, but was adjusted as required by the clinical team. Physiological variables (heart rate, mean blood pressure, and blood gases), ventilator settings, and plasma cortisol and catecholamine concentrations were measured before loading, and six hours after starting treatment. Blood specimens for hormonal analysis were centrifuged and the separated plasma stored at $-25^{\circ} \mathrm{C} . .^{10}$

Severity of illness was assessed using the arterial:alveolar oxygen partial pressure (a:A) ratio. ${ }^{12}$ Statistical analysis of data was performed using the Wilcoxon signed rank test for paired data, the Mann-Whitney $U$ test for unpaired data, Spearman's rank correlation coefficient, and the $\chi^{2}$ test for categorical data. Ethical approval for the study was granted, and written parental consent was obtained for each infant. 


\begin{tabular}{lllll}
\hline & Baseline median (range) & 6 hours median (range) & $\begin{array}{l}\text { Change 0 to 6 hours } \\
\text { median (range) }\end{array}$ & Significance \\
\hline Mean blood pressure (mm Hg) & $35(23-57)$ & $32(18-53)$ & $-4(-15$ to +9$)$ & $\mathrm{P}=0.0001$ \\
Heart rate (bpm) & $149(114-195)$ & $143(109-197)$ & $-3(-34$ to 70$)$ & $\mathrm{P}>0.05$ \\
Arterial $\mathrm{pH}$ & $7.29(6.86-7.56)$ & $7.29(7.11-7.51)$ & $-0.01(-0.15$ to +0.42$)$ & $\mathrm{P}>0.05$ \\
$\mathrm{pO}_{2}(\mathrm{kPa})$ & $7.9(3.5-20.0)$ & $7.9(4.0-15.8)$ & $-0.10(-10.9$ to +7.9$)$ & $\mathrm{P}>0.05$ \\
$\mathrm{pCO}_{2}(\mathrm{kPa})$ & $5.4(2.9-12.8)$ & $5.3(2.9-8.5)$ & $+0.18(-7.8$ to +2.6$)$ & $\mathrm{P}>0.05$ \\
Noradrenaline (nmol/l) & $2.40(0.87-14.13)$ & $1.51(0.63-14.7)$ & $-0.71(-7.2$ to +1.3$)$ & $\mathrm{P}<0.0005$ \\
Adrenaline $(\mathrm{nmol} / \mathrm{l})$ & $0.33(0.11-2.83)$ & $0.19(0.04-2.91)$ & $-0.11(-1.5$ to +1.8$)$ & $\mathrm{P}<0.005$ \\
Cortisol $(\mathrm{nmol} / \mathrm{l})$ & $364(47-8041)$ & $162(26-7799)$ & $-96(-1712$ to +2278$)$ & $\mathrm{P}=0.005$ \\
\hline
\end{tabular}

\section{Results}

Sedation was started at a median age of 15 hours (range 3 to 64). Baseline and 6 hour physiological and hormonal data are summarised in table 1 . No significant changes in heart rate or blood gases occurred, but a small, significant fall in mean blood pressure was observed. Stress hormone values also showed a significant fall over the six hour period (Wilcoxon signed rank test).

Figure 1 shows the correlation between stress hormone and a:A ratio values, with combined data from baseline and 6 hours displayed for each infant. Data analysis using Spearman's rank correlation coefficient was performed separately on baseline and 6 hour data, yielding a significant negative correlation for noradrenaline at both times: rho $=-0.57$ and -0.52, $(P<0.0005$ and $<0.005)$ for 0 and six hours, respectively. For adrenaline the corresponding values were: rho $=-0.30$ and -0.42 $(\mathrm{P}=0.05$ and $<0.01)$, and for cortisol rho $=$
-0.33 and $-0.30(P<0.05$ and $P=0.05)$. Fifteen infants died, at a median age of 6 days. Contributory factors included intraventricular haemorrhage (grade 3 or worse) in seven, pneumothorax in five, septicaemia in three, patent ductus arteriosus treated with indomethacin in four, and pulmonary haemorrhage in one. Among the survivors the median duration of ventilation was five days. Fifteen infants $(47 \%)$ developed bronchopulmonary dysplasia (defined as a requirement for supplemental oxygen at 36 weeks postconceptional age), of whom five were subsequently discharged on home oxygen treatment. Two infants developed intraventricular haemorrhage (grade 3 or worse), seven had a pneumothorax, and eight (25\%) received treatment with indomethacin for a patent ductus arteriosus.

Birth details and physiological variables before starting treatment with diamorphine were compared between fatalities and survivors
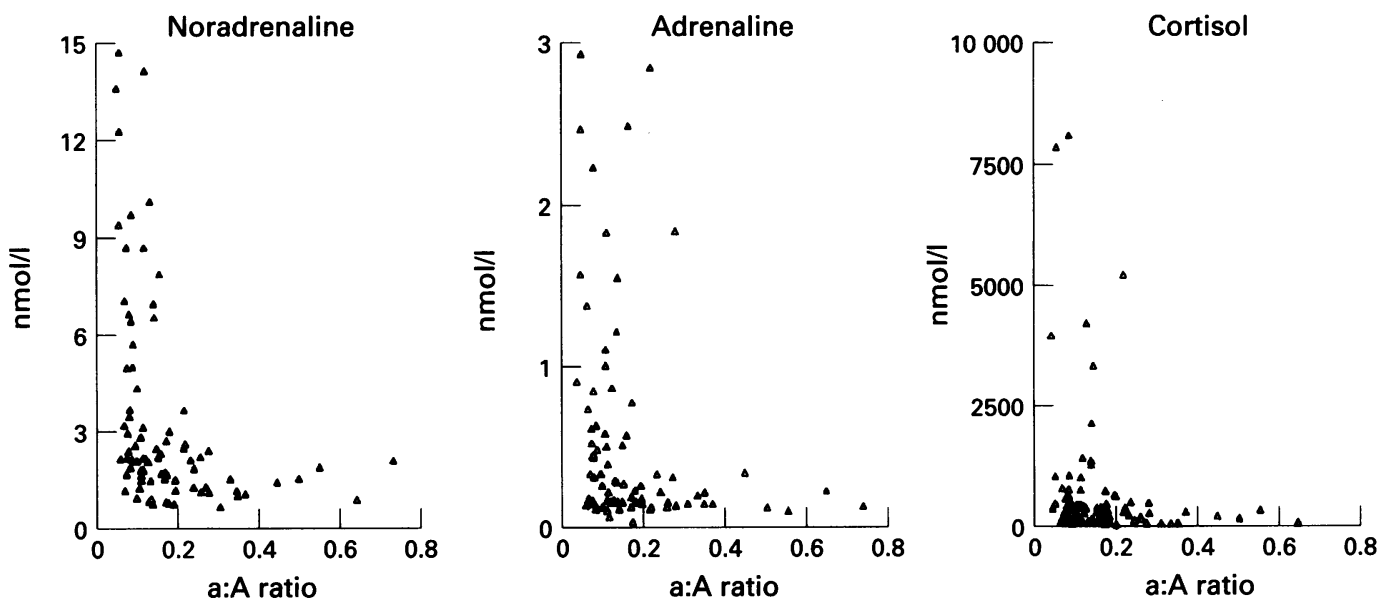

Figure 1 Stress hormone response compared with severity of illness
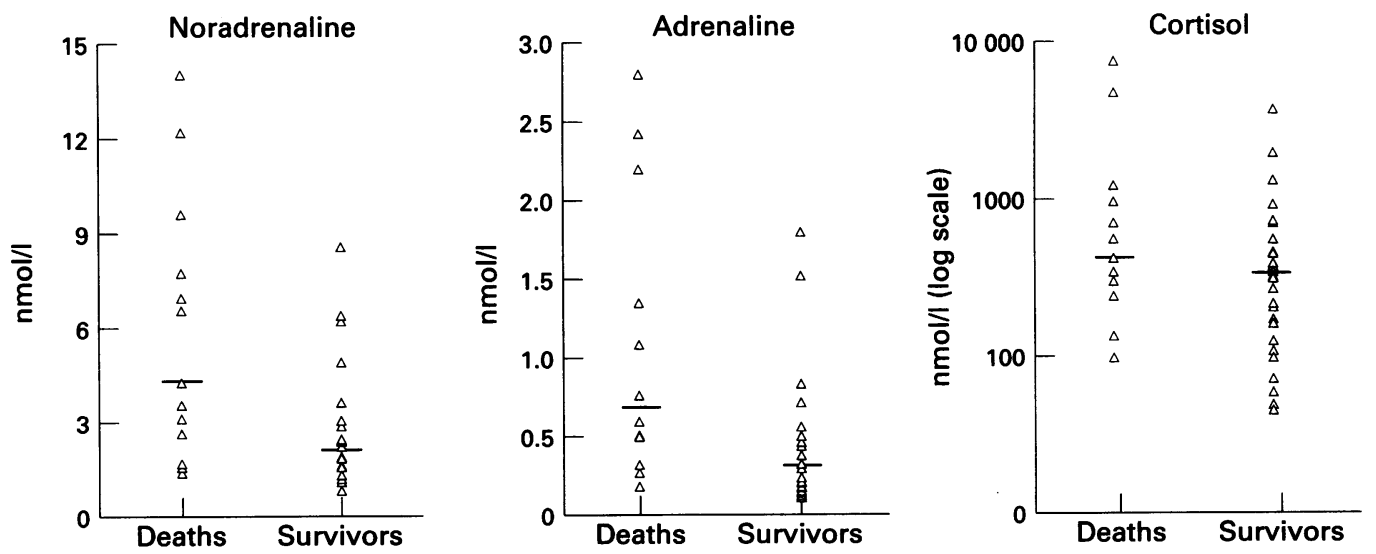

Figure 2 Baseline stress hormone values and outcome 
Table 2 Comparison of infant characteristics: death vs survivors

\begin{tabular}{|c|c|c|c|}
\hline & $\begin{array}{l}\text { Deaths ( } n=15 \text { ) } \\
\text { median (range) }\end{array}$ & $\begin{array}{l}\text { Survivors }(n=32) \\
\text { median (range) }\end{array}$ & Significance \\
\hline Gestation (weeks) & $26(24-30)$ & $29(25-35)$ & $P=0.0001$ \\
\hline Birth weight (kg) & $0.84(0.68-1.72)$ & $1.31(0.52-3.04)$ & $P<0.001$ \\
\hline Vaginal delivery & $10(67 \%)$ & $13(41 \%)$ & $P>0.05$ \\
\hline \multicolumn{4}{|l|}{ Apgar score } \\
\hline 1 minutes & $2(1-9)$ & $5(1-9)$ & $\mathrm{P}<0.005$ \\
\hline 5 minutes & $6(1-9)$ & $8(4-10)$ & $\mathrm{P}<0.005$ \\
\hline Age at starting sedation (hours) & $15(3-60)$ & $18(4-64)$ & $P>0.05$ \\
\hline $\mathrm{FIO}_{2}$ & $0.79(0.46-1.00)$ & $0.68(0.22-1.00)$ & $P<0.05$ \\
\hline Arterial pH & $7.26(7.11-7.37)$ & $7.31 \quad(6.86-7.56)$ & $P>0.05$ \\
\hline $\mathrm{pO}_{2}(\mathrm{kPa})$ & $7.8(4.4-13.8)$ & $7.95(3.5-20)$ & $P>0.05$ \\
\hline $\mathrm{pCO}_{2}(\mathrm{kPa})$ & $5.6(4.7-8.9)$ & $5.3(2.9-12.78)$ & $P>0.05$ \\
\hline Heart rate (bpm) & $155(130-195)$ & $142(114-173)$ & $P<0.05$ \\
\hline Mean blood pressure $(\mathrm{mm} \mathrm{Hg})$ & $30(23-40)$ & $37(27-57)$ & $P=0.001$ \\
\hline
\end{tabular}

(table 2). Infants who died were of significantly lower gestational age and birthweight, with significantly lower Apgar scores and mean blood pressures. Baseline heart rate and inspired oxygen requirements were significantly higher. However, the age at which diamorphine was started and baseline arterial blood gas variables did not differ significantly between groups.

Figure 2 shows baseline stress hormone values for infants who died and survived. Complete data were obtained from 41 infants $(87 \%)$, with at least one hormone measured in the remaining six infants (three fatalities and three survivors). Plasma catecholamine values were significantly higher among infants who died (median noradrenaline 4.31 vs 2.16 $\mathrm{nmol} / \mathrm{l}, \mathrm{P}<0.05$; median adrenaline 0.69 vs $0.31 \mathrm{nmol} / 1, P<0.005)$. Plasma cortisol values did not differ significantly between groups (median cortisol 443 vs $352 \mathrm{nmol} / \mathrm{l}, \mathrm{P}=0.08$, Mann-Whitney U test).

Figure 3 shows changes in noradrenaline concentrations between 0 and 6 hours for
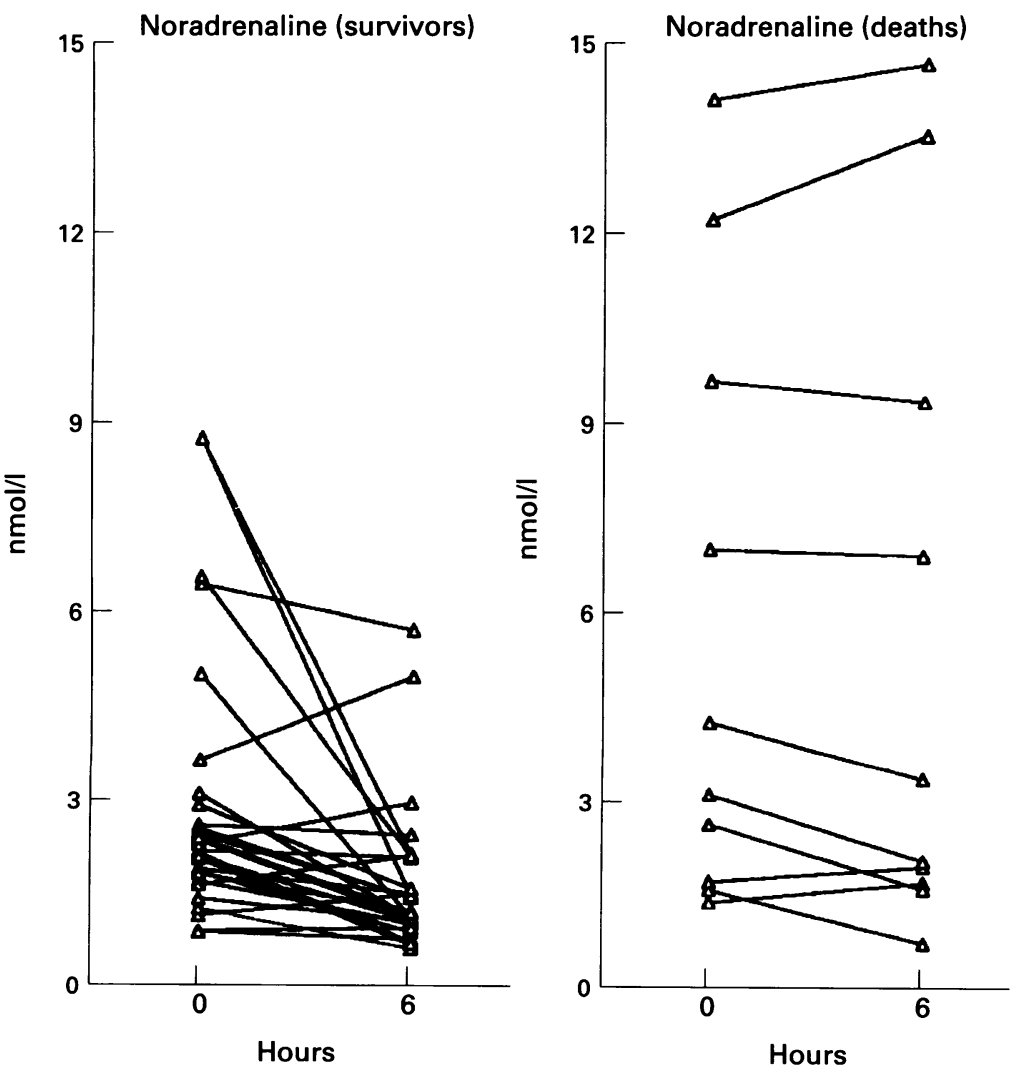

Figure 3 Noradrenaline response to sedation infants in whom paired samples were available for analysis. There was a median fall of $2 \%$ among infants who died, compared with a $40 \%$ fall among survivors $(\mathrm{P}=0.06$, Mann-Whitney $\mathrm{U}$ test). For adrenaline and cortisol the median change (fall) observed was similar for those who died and survivors (adrenaline $22 \%$ vs $23 \%$, cortisol $35 \%$ vs $46 \%$ ).

\section{Discussion}

Stress may be defined as an antagonistic state resulting from factors threatening the homeostasis or wellbeing of an organism, and the resistance offered. Although stress responses are generally considered beneficial, stress tolerance can be exceeded, leading to distress. ${ }^{12}$ Fetal stress responses to invasive procedures occur from as early as 23 weeks of gestation, ${ }^{13}$ and the existence of a "fetal stress syndrome" has been postulated, with adverse effects on development and brain growth. ${ }^{14}$ Supportive evidence comes from animal studies in which glucocorticoids were found to exacerbate hypoxic-ischaemic neuronal damage, with high values associated with damage to the hippocampus. ${ }^{15}{ }^{16}$ Hormonal stress responses to surgical procedures in neonates are well documented. There is some evidence from such studies that extreme postnatal stress may also be pathological, increasing postoperative morbidity and mortality. ${ }^{12}$ Potential sources of stress for the sick preterm infant include respiratory disease, recurrent handling and procedures, and high ambient levels of noise and light. ${ }^{17}$ Stress responses in these circumstances are poorly defined and difficult to equate with those associated with, for example, thoracotomy. However, Hughes et al reported that unsedated sick preterm infants achieve cortisol values on the fourth to fifth day of life which exceed those seen in response to surgery. ${ }^{18}$ Opiates attenuate cortisol and catecholamine responses, ${ }^{6}$ but whether this produces therapeutic benefit is currently uncertain. ${ }^{19}$

Indications for starting opiate treatment vary between units, but from those stated here it is reasonable to assume that infants in this study were substantially stressed. The a:A ratio was chosen to represent severity of illness because respiratory disease was likely to have been the predominant stress factor at this time. Thirty nine infants $(83 \%)$ had a:A ratios below 0.22 , indicating illness of at least moderate severity, ${ }^{20}$ and many were extremely unwell (shown by the high rate of complications among survivors). Most infants received surfactant before sedation was begun. Surfactant administration has little immediate effect on catecholamine concentrations. ${ }^{21}$

The ability of some extremely preterm infants to mount stress hormone responses has been questioned. ${ }^{52}$ Cortisol and $\beta$-endorphin have been studied in the most detail, with infants often simply categorised as well or unwell. ${ }^{23}$ The pattern of catecholamine response seen here, with the most extreme responses in the sickest, most premature infants, has not been reported before, as far as we are aware. Noradrenaline correlated most 
strongly with severity of illness. This supports the concept of noradrenaline being a marker of persistent stress, or pain, as proposed by Quinn et al. $^{24}$

The infants who died were of significantly lower gestational age and birthweight. Increased oxygen requirements before sedation suggests that their clinical condition was worse, and this is consistent with the significant increases in heart rate and catecholamine values observed in these infants. Catecholamine secretion can be influenced by mode of delivery, postnatal age, and inotropes. ${ }^{25-27} \mathrm{~A}$ greater proportion of deaths (although not significant) followed vaginal delivery, which is associated with higher initial catecholamine values, but these fall rapidly after birth. ${ }^{28}$ Postnatal age was very similar between groups, and the number of infants receiving dopamine was small (two in each group at the time of starting sedation). Cortisol is known to behave in a similar manner to catecholamines in relation to mode of delivery and postnatal age. ${ }^{29} 30$ Reynolds found significantly increased cortisol values among infants with fatal hyaline membrane disease compared with infants with "benign" respiratory distress not requiring ventilation. ${ }^{31}$ In the present study cortisol values were not significantly higher among those who died, perhaps because all infants were ventilated, reducing the clinical difference between groups.

When changes in stress hormone concentrations between 0 and 6 hours were considered, a different pattern was observed between noradrenaline and the other hormones, with a reduced noradrenaline response to sedation among infants who died. This failed to achieve significance, but a striking lack of response was seen in some infants with very high values (fig 3). Persistently high noradrenaline values may therefore be of some prognostic importance.

The question remains as to whether increased stress hormones merely reflect severe underlying illness or whether they are clinically important in the aetiology of adverse outcome. Theoretical grounds exist for believing that extreme stress responses may be harmful. ${ }^{32}$ Our observations do not resolve, but they do support, this argument. We believe that the careful use of opiate sedation and analgesia in ventilated preterm infants is justified on humanitarian grounds, and the possibility exists that it may also improve outcome.

1 Anand KJS, Sippell WG, Aynsley-Green A. Randomised trial of fentanyl anaesthesia in preterm babies undergoin trial of fentes on the stress response. Lancet 1987;i:243-7.

Anand KJS, Hansen DD, Hickey PR. Hormonal-metabolic stress responses in neonates undergoing cardiac surgery. Anesthesiology 1990;73:661-70.

3 Anand KJS, Aynsley-Green A. Measuring the severity of surgical stress in newborn infants. F Ped Surg 1988;23:297-305. 4 Barker DP, Rutter N. Exposure to invasive procedures in 1995;72:F47-8.
5 Hanna CE, Keith D, Colasurdo MA, Buffkin DC, Laird MR, Mandel SH, et al. Hypothalamic pituitary adrenal function in the extremely low birth weight infant. $\mathcal{f}$ Clin Endocrin Metab 1993;76:384-7.

6 Quinn MW, Wild J, Dean HG, Hartley R, Rushforth JA, Puntis JWL, et al. Randomised double-blind controlled trial of effect of morphine on catecholamine concentrations in ventilated pre-term babies. Lancet 1993;342:324 7.

7 Pokela M-L. Effect of opioid-induced analgesia on betaendorphin, cortisol and glucose responses in neonates with
cardiorespiratory problems. Biol Neonate 1993;64:360-7.

8 Barker DP, Simpson J, Pawula M, Barrett DA, Shaw PN, Rutter N. Randomised, double blind trial of two loading dose regimens of diamorphine in vent
infants. Arch Dis Child 1995;73:F22-6.

9 Moore A, Aitken R, Burke C, Gaskel S, Groom G, Holder $\mathrm{G}$, et al. Cortisol assays: guidelines for the provision of clinical biochemistry service. Ann Clin Biochem 1985;22:435-53.

10 McDonald IA, Lake DM. An improved technique for extracting catecholamines from body fluids. 7 Neurosci Methods 1985;13:239-48.

11 Gilbert R, Keighley GF. The arterial/alveolar oxygen tension ratio: an index of gas exchange applicable to varying inspired oxygen concentrations. Am Rev Respir Dis 1974;109:142-5.

12 Ruth V. Neonatal stress or distress. $f$ Perinat Med 1991;19:S151-6.

13 Giannakoulopoulos X, Sepulveda W, Kourtis P, Glover V, Fisk NM. Fetal plasma cortisol and beta- endorphin
response to intrauterine needling. Lancet 1994;344:77-81.

14 Lou HC, Hansen D, Nordentoft M, Pryds O, Jensen F, Nim J, Hemmingsen R. Prenatal stressors of human life affect fetal brain development. Dev Med Child Neurol 1994;36:826-32.

15 Sapolsky RM, Pulsinelli W. Glucocorticoids potentiate ischaemic injury to neurones: therapeutic implications. Science 1985;229:1397-9.

16 Sapolsky RM, Uno H, Rebert CS, Finch CE. Hippocampal damage associated with prolonged glucocorticoid exposure in primates. $\mathcal{F}$ Neurosci $1990 ; 10: 2897-902$.

17 Wolke D. Environmental neonatology. Arch Dis Child 1987;62:987-8.

18 Hughes D, Murphy JF, Dyas J, Robinson JA, Riad- Fahmy D, Hughes I. Blood spot glucocorticoid concentrations in ill preterm infants. Arch Dis Child 1987;62:1014-18.

19 Wolf AR. Treat the babies, not their stress responses. Lancet 1993;342:319.

20 OSIRIS collaborative group. Early versus delayed neonatal administration of a synthetic surfactant - the judgement of OSIRIS. Lancet 1992;340:1363-9.

21 Chan JO, Moglia BA, Reeves IV, Kim AH, Darrow KA, Seaton JF, et al. Cardiorespiratory and stress hormone responses during first dose surfactant administration in neonates with RDS. Pediatr Pulmonol 1994;17:246-9.

22 Lee MM, Rajagopalan L, Berg GJ, Moshang T. Serum adrenal steroid concentrations in premature infants. $f$ Clin adrenal steroid concentrations in

23 Hindmarsh KW, Sankaran K, Watson VG. Plasma betaendorphin concentrations in neonates associated with acute stress. Dev Pharmacol Ther 1984;7:198-204.

24 Quinn MW, Otoo F, Rushforth JA, Dean HG, Puntis JWL, Wild J, et al. Effect of morphine and pancuronium on the stress response in ventilated preterm infants. Early Hum Dev 1992;30:241-8.

25 Greenough A, Lagercrantz H, Pool J, Dahlin I. Plasma catecholamine levels in preterm infants. Effect of birth

26 Eliot RJ, Lam R, Leake RD, Hobel CJ, Fisher DA. Plasma catecholamine concentrations in infants at birth and during the first 48 hours of life. $\mathcal{F}$ Pediatr 1980;96:311-15.

27 Stopfkuchen H, Racke K, Schworer H, Queisser-Luft A, Vogel K. Effects of dopamine infusion on plasma catechologel $\mathrm{K}$. Effects of dopamine newborn infants. Eur $₹$ Pedilamines in preterm and

28 Lagercrantz H, Slotkin TA. The "stress" of being born Scientific American 1986;254:92-102.

29 Kauppila A, Koivisto M, Pukka M, Tuimala R. Umbilica cord and neonatal cortisol levels. Effect of gestational and neonatal factors. Obstet Gynaecol 1978;52:666-72.

30 Kraiem Z, Sack J, Brish M. Serum cortisol levels: the firs ten days in full-term and preterm infants. Israel f Med Sci 1985;21:170-2.

31 Reynolds JW. Serum total corticoid and cortisol levels in premature infants with respiratory distress syndrome. Pediatrics 1973;51:884-90.

32 Anand KJS. Relationships between stress responses and clinical outcome in newborns, infants and children. Crit Care Med 1993;21:S358-9. 